\title{
O que um designer estará projetando em 2065? Inquietações e contribuições do Laboratório de Arte Eletrônica
}

\author{
What will a designer be designing in 2065? \\ Concerns and contributions of the Electronic Art Lab
}

\author{
Rejane Spitz, Laboratório de Arte Eletrônica, PUC-Rio \\ rejane@puc-rio.br
}

\begin{abstract}
Resumo
Ao longo das ultimas décadas, a Mídia Digital ganhou espaço e se consolidou como campo essencial do Design. Hoje, além de conhecer as diversas tecnologias digitais e de estar apto a lidar com as constantes mudanças tecnológicas, um designer precisa ser também capaz de vislumbrar, propor e desenvolver cenários futuros imprevisíveis. Neste artigo discutimos as origens do ensino de Mídia Digital nas Artes \& Design, destacando o pioneirismo do Laboratório de Arte Eletrônica (LAE) da PUC-Rio, espaço interdisciplinar de pesquisa e produção de projetos digitais. Apresentamos os aspectos teóricos e metodológicos que norteiam os projetos do LAE e discutimos sua contribuição acadêmica. A partir da análise do cenário atual e prospecções sobre o futuro, sublinhamos, em conclusão, a importância da formação de profissionais de Design capacitados a atuar de forma crítica, inclusiva, inovadora, eficiente e responsável, para a construção de um futuro no qual as mídias digitais estejam sempre a serviço da melhoria da qualidade de vida.
\end{abstract}

Palavras-chave: design, mídia digital, arte eletrônica, educação

\begin{abstract}
Over the last few decades, Digital Media has gained space and consolidated itself as an essential field of Design. Today, in addition to knowing the different digital technologies and being able to deal with constant technological changes, a designer must also be able to envision, propose and develop unpredictable future scenarios. In this article we discuss the origins of Digital Media teaching in Arts \& Design, highlighting the pioneering spirit of the Electronic Art Laboratory (LAE) at PUC-Rio - an interdisciplinary space for research and production of digital projects. We present the theoretical and methodological aspects that guide LAE projects and discuss their academic contribution. Based on the analysis of the current scenario and prospects for the future, we underline, in conclusion, the importance of training Design professionals to act in a critical, inclusive, innovative, efficient and responsible manner, for the construction of a future in which digital media is always at the service of improving the quality of life.
\end{abstract}

Keywords: design, digital media, electronic art, education 


\section{Tecnologias digitais: novos horizontes para o ensino de Artes \& Design}

Os anos 80 marcaram o início de uma época extremamente fértil para o ensino de Artes e Design: a rápida evolução da tecnologia computacional - e sua coexistência com práticas artísticas seculares - permitiam uma interessante confrontação entre o tradicional e o novo. Havia uma crescente efervescência em relação ao potencial expressivo dessa nova tecnologia, e uma enorme curiosidade quanto à sua contribuição ao ensino. Buscava-se definir e nomear as novas categorias artísticas, porém tornava-se cada vez mais difícil "deixar claro quais tipos de trabalhos se encaixavam ou não em cada categoria e/ou subcategoria" (FLORINDO et al, 2018, p. 108). Alguns dos inúmeros termos surgidos para nomear novas formas de arte produzidas com o auxílio - ou por meio - de tecnologias digitais são descritos por BERNARDINO (2010), que sublinha a importância da terminologia:

No final do século XX foram incorporados termos, na história e na teoria da arte, que abundam de neologismos, tais como: cyberart, realidade virtual, telemática, interface, software art, real time, vida artificial, fractal art, robótica, net.art, web.art, hipermédia, distopia, cyborgs, bio art etc. Toda essa invasão não é apenas uma questão de neologia (criação de vocabulários), pelo contrário, essa nova terminologia alude a questões fundamentais, centrais e altamente relevantes em termos quer da arte (na redefinição das práticas implícitas que têm sido aceitas pela comunidade artística contemporânea) quer da ciência. (p. 48)

Diante dessa infinita gama de possibilidades, foi cunhado o termo Arte Eletrônica, que abrange, de modo genérico e holístico, o campo teórico-prático que explora novas possibilidades de expressão, percepção, cognição e comunicação, através de combinações originais e múltiplas entre arte, design, ciência e tecnologia (HOLANDA \& SPITZ, 2008; SPITZ, 2014).

E embora, no meio acadêmico, a tecnologia computacional já estivesse presente nos laboratórios técnico-científicos, naquele momento embrionário eram raras as universidades que dispunham de equipamentos computacionais no âmbito das Artes \& Design. Por isso, grande parte dos pioneiros de Arte Eletrônica buscou o estabelecimento de parcerias junto a empresas e laboratórios de Ciências da Computação, trabalhando em colaboração com cientistas (COX, 1987).

Até meados dos anos 80 - mesmo em países desenvolvidos - o conhecimento e uso de recursos computacionais por parte de artistas e designers era praticamente nulo. Tive oportunidade de vivenciar essa situação durante meus cursos de pós-graduação em Design, na Inglaterra (19811983): embora a computação gráfica já começasse a florescer na indústria britânica, nenhuma disciplina relacionada à essa tecnologia estava sendo oferecida aos alunos de suas instituições de Design. Coincidentemente, minha entrada na área de Computação Gráfica deu-se durante esse mesmo período: em 1982, fui selecionada para atuar como animadora em computação gráfica numa empresa londrina, utilizando o sistema Aurora ${ }^{1}$. De forma totalmente autodidata, tive que desenvolver minhas próprias técnicas e criar um portfolio de animações em computação gráfica. Para a apresentação de minha defesa do Mestrado, em 1983, criei uma animação em Computação

\footnotetext{
1 Empresa norte-americana, fundada em 1979 por Richard Shoup - desenvolvedor do pioneiro sistema SuperPaint, no inicio dos anos 70, quando atuava na Xerox PARC, Califórnia.
} 
Gráfica, e meus professores se admiraram ao saber que eu tinha acesso a esses sofisticados recursos, totalmente inexistentes no âmbito universitário.

Após 2 anos atuando como animadora em Computação Gráfica ${ }^{2}$ - fui contratada, em 1995, pelo Departamento de Artes \& Design da PUC-Rio, trazendo comigo a experiência adquirida nessa área, e o sonho de introduzir novas ideias, disciplinas e projetos relacionados à tecnologia computacional no âmbito acadêmico de Artes \& Design. Já no ano seguinte, em paralelo às atividades de ensino, iniciava meu Doutorado, cujo objetivo era investigar questões sobre o ensino de Computação Gráfica para Artes \& Design (SPITZ, 1993).

Em 1987, começamos a oferecer disciplinas de Introdução à Computação Gráfica nos cursos de graduação em Design da PUC-Rio, mas - para além das aulas - queríamos criar também um espaço de experimentação multidisciplinar, que ampliasse a interlocução acadêmica entre as áreas de Artes, Design e Ciências da Computação, e propiciasse a formação de profissionais híbridos em aspectos artísticos e tecnológicos.

\title{
Laboratório de Arte Eletrônica: um espaço híbrido, visionário e responsável
}

Em 1992 foi criado, no Departamento de Artes \& Design, o Núcleo de Arte Eletrônica (NAE) - que posteriormente passou a se chamar Laboratório de Arte Eletrônica (LAE) - lócus que abriga alunos e docentes de Artes, Design, Ciência da Computação e outras áreas do saber, que, de forma integrada, criam, desenvolvem e produzem pesquisas e projetos no campo da Mídia Digital, subsidiados por agências de fomento à pesquisa, ou em parceria com instituições e empresas.

A conquista desse espaço experimental - o primeiro de sua natureza no Brasil - foi facilitada pelo pioneirismo da iniciativa, por nossa inserção em associações profissionais internacionais e representatividade nas principais conferências de Arte Eletrônica e Computação Gráfica, e, ainda, pela obtenção de equipamento computacional sofisticado, que nos foi doado, em 1991, pela Sun Microsystems.

Em 1999, fizemos uma avaliação da contribuição do Laboratório, apresentando os resultados obtidos nos seus primeiros anos de existência:

\begin{abstract}
A despeito de suas limitações físicas e financeiras, e de seu caráter experimental, o Núcleo de Arte Eletrônica serve como um modelo para a criação de laboratórios de ensino e pesquisa vinculados aos cursos de graduação de Design. Parece-nos ser fundamental a existência de laboratórios como este, que permitam aos docentes e alunos de Design a atualização de seus conhecimentos e a atividade prática projetual em áreas de ponta, com recursos adequados, em compasso com os desenvolvimentos da indústria, no espaço do próprio ensino. A tecnologia computacional vem infiltrando-se de tal forma no cotidiano da sociedade moderna, que, dentro de poucos anos, toda essa discussão a respeito do papel da Computação na área de Design terá apenas um sentido histórico. Ainda assim, acredita-se que este seja um momento extremamente fértil para que se avalie a filosofia, os objetivos e a prática do ensino de Artes \& Design, e para que se repense nos modelos de parcerias entre universidade e instituições extra-muros que permitam a oxigenação do ensino e a constante atualização do saber acadêmico. (SPITZ, 1999, p.18)
\end{abstract}

\footnotetext{
2 Na Pullman Video \& Graphics, Londres (1982-1984) e na Divisão de Computação Gráfica da TV Globo, Rio de Janeiro (1984-1985).
} 
Desde então, o Laboratório de Arte Eletrônica vem atuando de forma inovadora e inclusiva, desenvolvendo projetos sobre temáticas como analfabetismo digital, saúde publica, segurança alimentar, meio ambiente e sustentabilidade. Temos por pressuposto que nossos projetos devem sensibilizar, engajar e transformar o cidadão, de modo a proporcionar a melhoria das condições de vida no planeta.

Ao longo de seus mais de 25 anos de existência foram desenvolvidos pesquisas e projetos relacionados a problemas sociais e demandas públicas ${ }^{3}$. $\mathrm{Na}$ área da saúde e prevenção de doenças, atuamos em projetos relacionados à testagem de acuidade visual em crianças pré-alfabetizadas (SPITZ, 1983, 1989), advertências sanitárias contra o fumo (NASCIMENTO et al, 2010; SZKLO et al, 2009; SPITZ e GAMBA Jr., 2007) (Fig. 1), informações médicas sobre procedimentos relativos ao parto e ao nascimento (SPITZ et al, 2017) (Fig. 2) e prevenção de doenças por ingestão de aditivos químicos em alimentos processados (SPITZ et al, 2018) (Fig. 3).
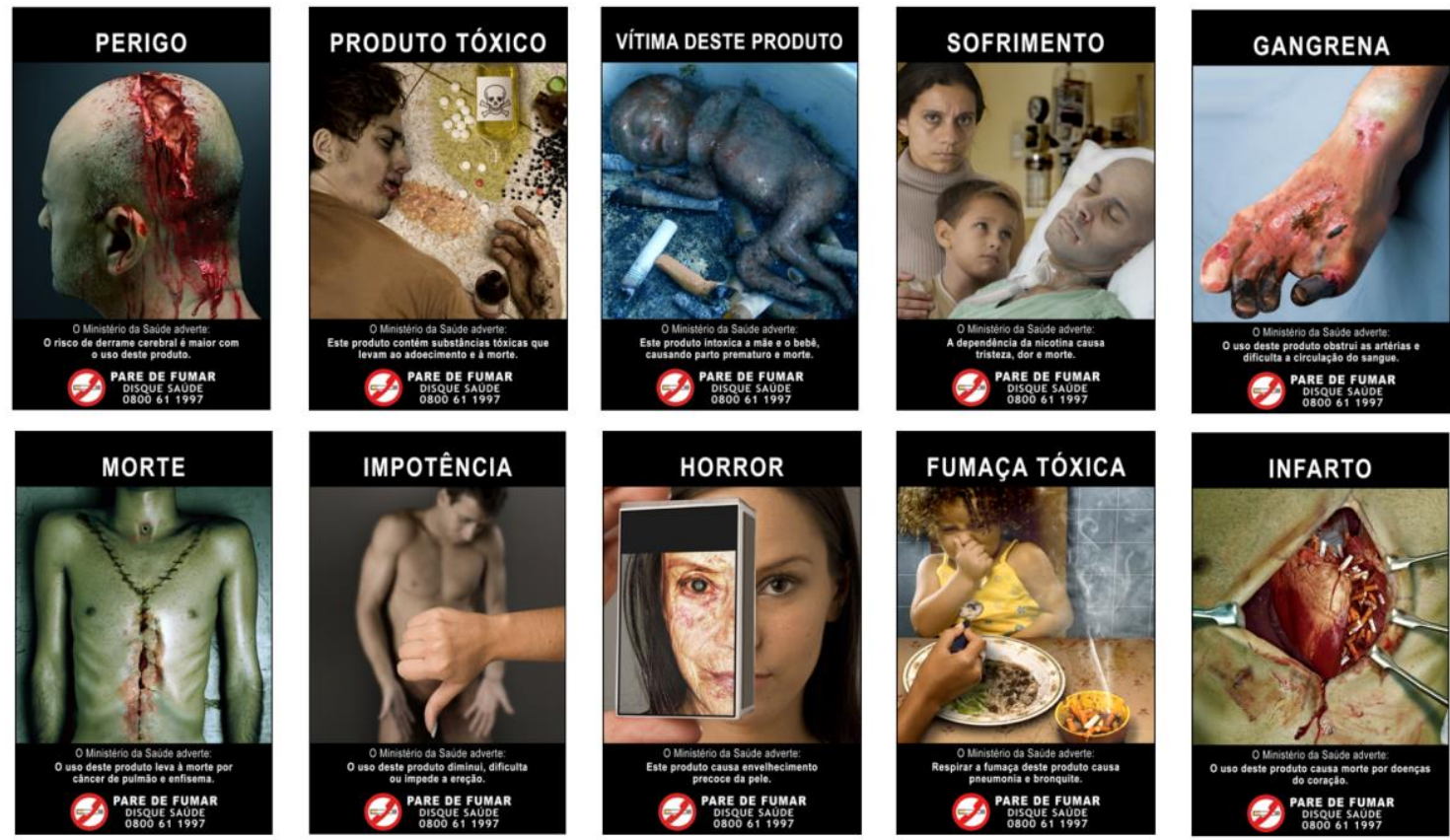

Figura 1- imagens e frases de advertências para maços de cigarros brasileiros - campanha lançada nacionalmente pelo Ministério da Saúde do Brasil, que permaneceu em circulação de 2008 a 2018.

\footnotetext{
3 Em parceria com instituições tais como INCA, FIOCRUZ, ANVISA, Universidade Federal do Rio de Janeiro (UFRJ), Universidade Federal Fluminense (UFF), Universidade Federal de Sergipe (UFS), Universidade Federal de Minas Gerais (UFMG), Secretaria de Estado da Educação de Sergipe (SEED-SE), ISAST, ACM SIGGRAPH, FAPERJ, FINEP, FIERJ, CAPES, CNPq e Bill \& Melinda Gates Foundation, dentre outras.
} 

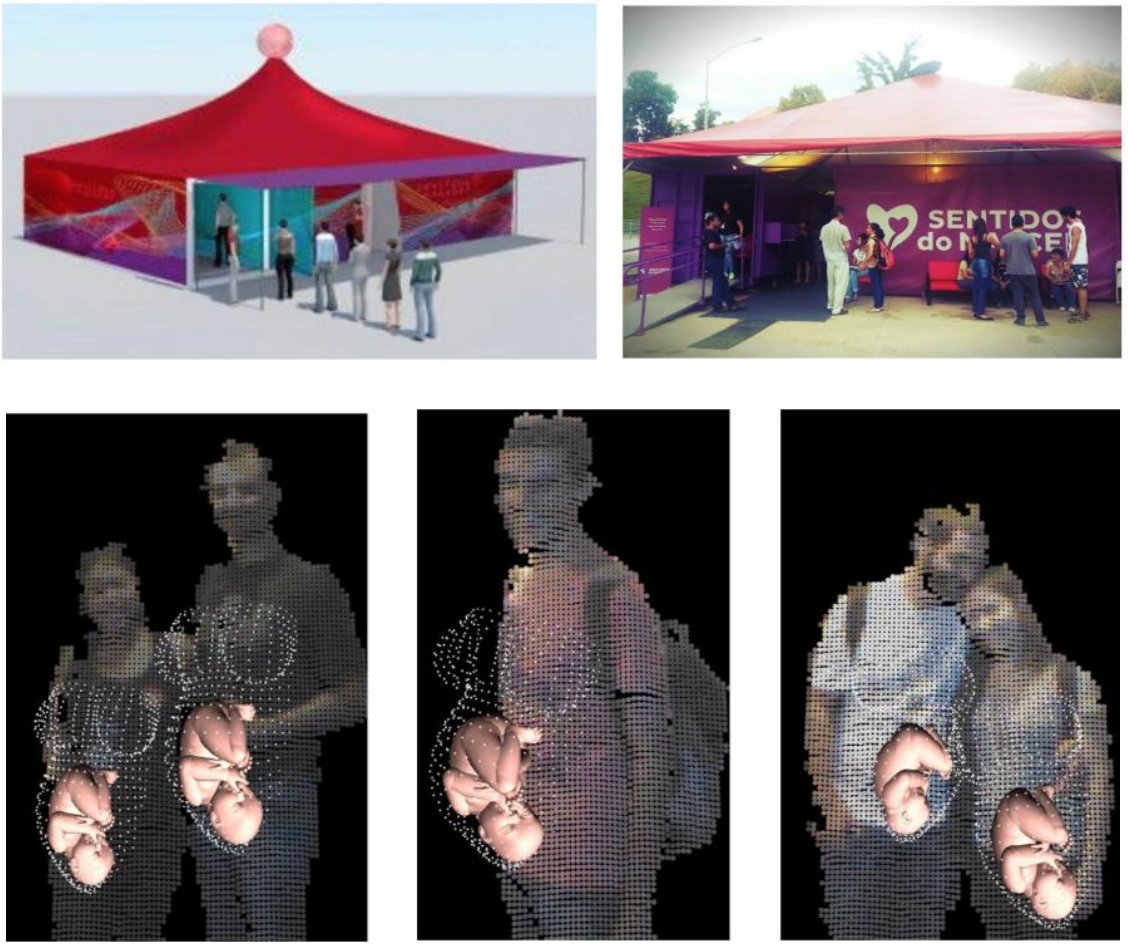

Figura 2 - detalhes da exposição "Sentidos do Nascer" (2015-2016)
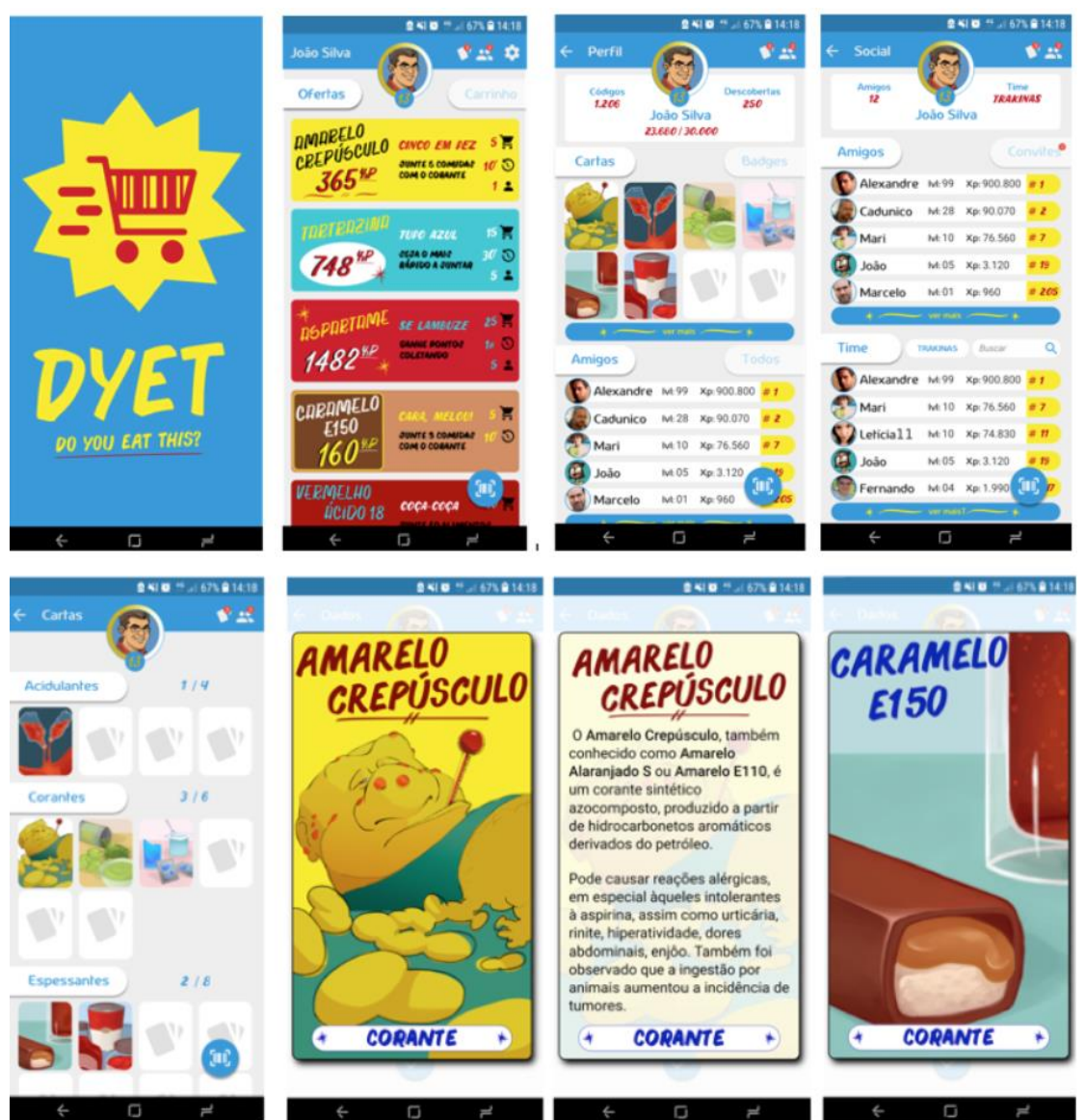

Figura 3- telas do aplicativo gamificado “DYET - Do You Eat This?” (2016-2018) 
Trabalhamos ainda com questões de preservação do meio ambiente e popularização da ciência (SPITZ, 2010) (Fig. 4), analfabetismo digital (SPITZ, 2001) (Fig. 5), fome e desnutrição (SPITZ, 2004, 2005) (Fig. 6), e educação (SPITZ, 1993, 2000, 2014).
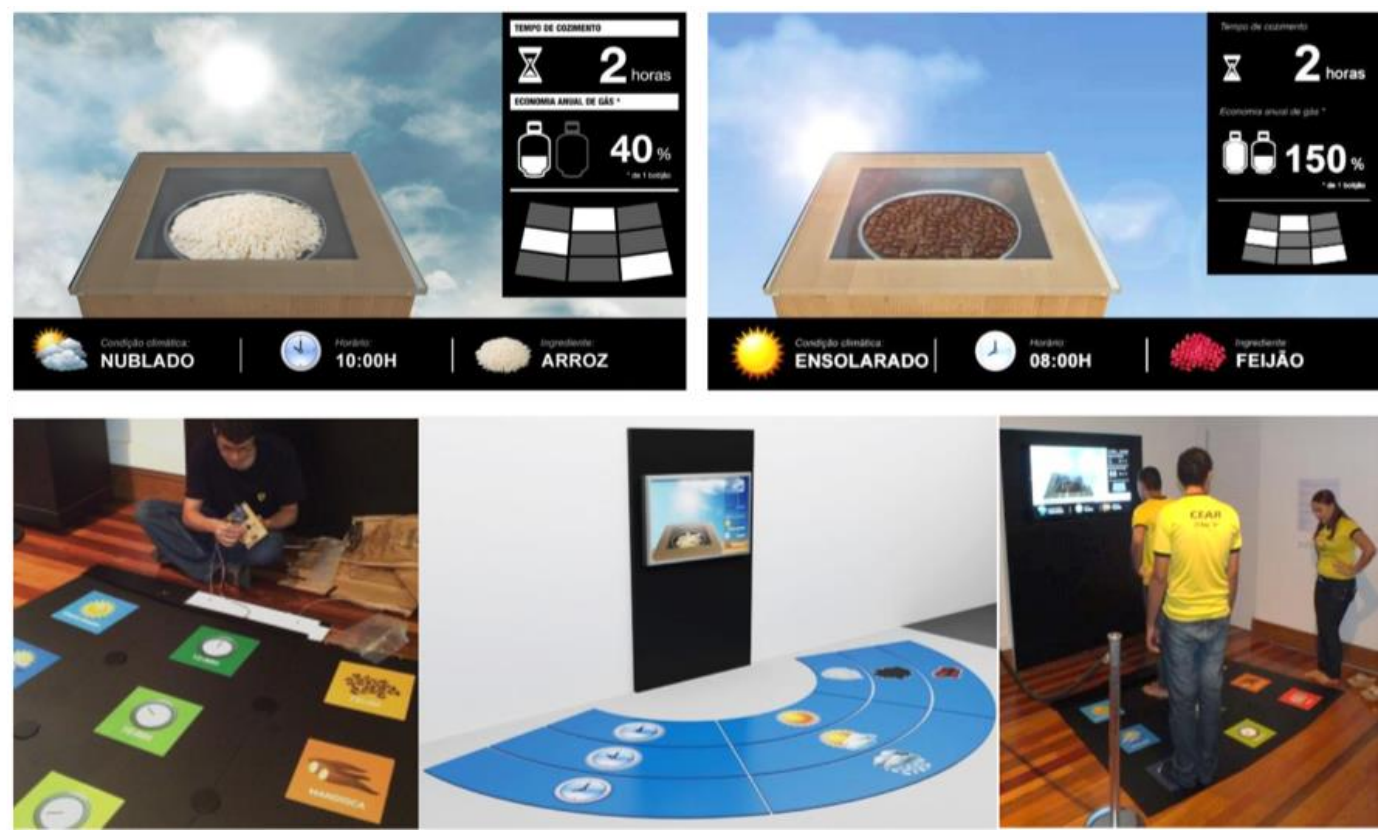

Figura 4- detalhes da instalação "Fogão Solar”, exibida no Museu da Gente Sergipana, Aracaju, Sergipe, em 2013.
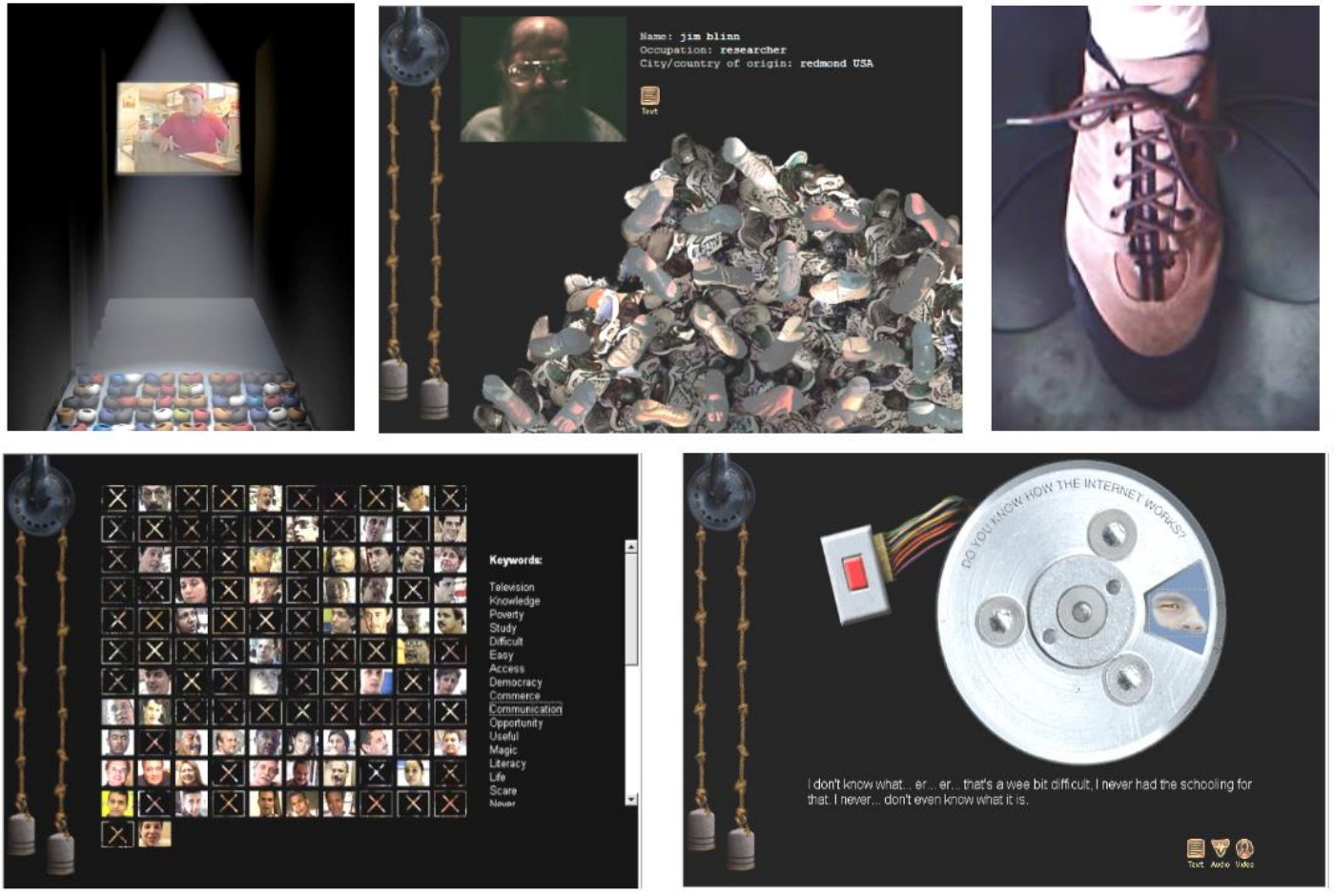

Figura 5 -detalhes da instalação "Netizens, Net-fringers and Outsiders" (1999 - 2001) 

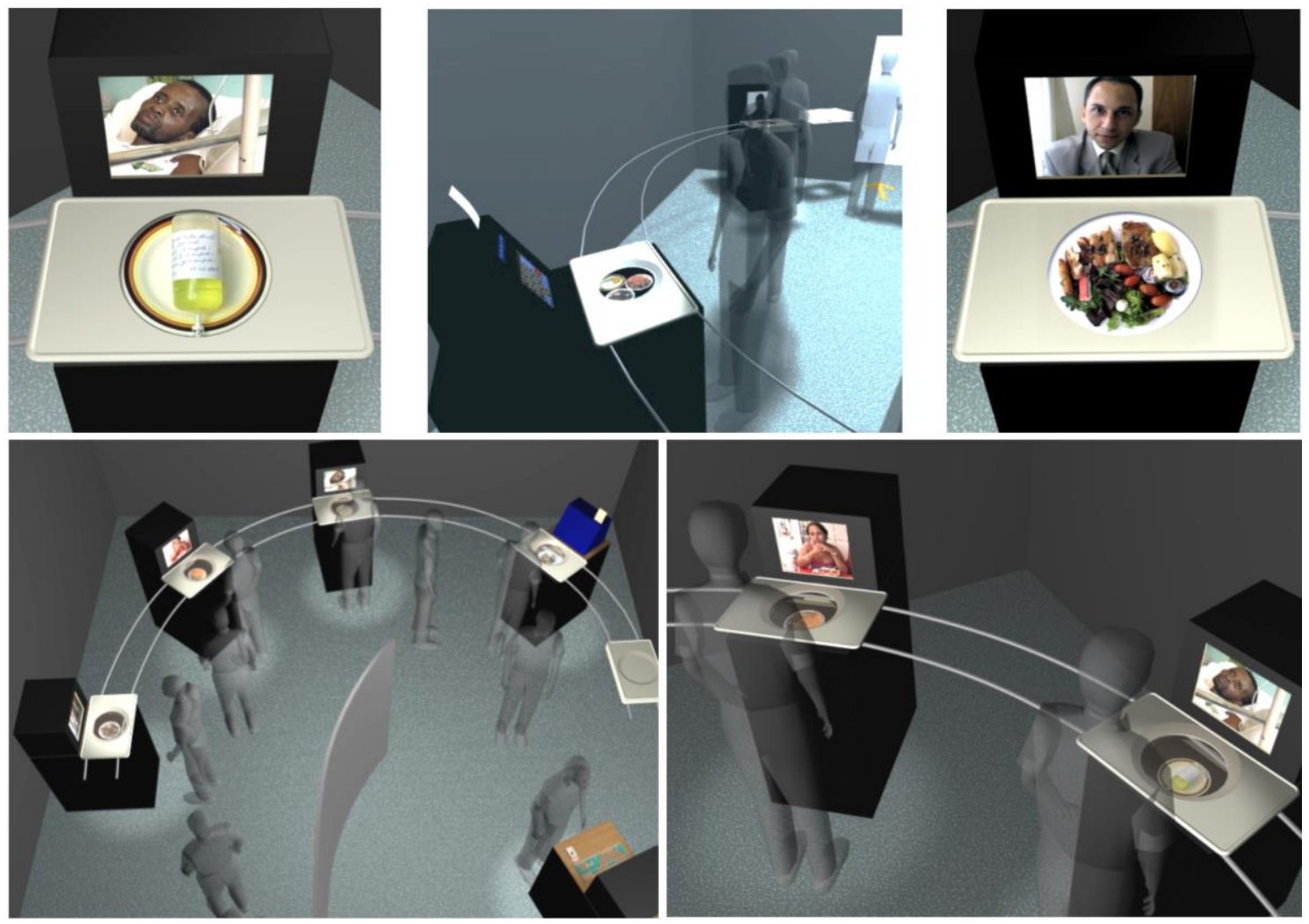

Figura 6 -detalhe da instalação "Você tem fome de que?" (2003-2005)

Nossos trabalhos demandam a formação de equipes multidisciplinares e multifacetadas, exigindo empenho e colaboração. Segundo COX (1987), a partir da invenção da Computação Gráfica, artistas e cientistas começaram a ter mais pontos de convergência, através do uso de ferramentas semelhantes e de sua participação no que ela chama de "equipes renascentistas". Nessa linha, o compartilhamento dos saberes é também muito incentivado no LAE: nossa metodologia de trabalho requer que todos os integrantes atuem em todas as fases dos projetos, desempenhando diferentes atividades e contribuindo em diferentes áreas. Nossa visão está em consonância também com a de Paulo Freire, que percebe a educação como um processo construído de forma holística, através da inclusão de todos os participantes, em uma relação dialógica e recíproca: "Ninguém educa ninguém, ninguém se educa a si mesmo, os homens se educam entre si, mediatizados pelo mundo" (FREIRE, 1987, p. 34).

Apesar de contarmos, na equipe, com pessoas com formações diferenciadas, é feito um trabalho pedagógico no sentido de: fortalecer as individualidades, reduzir o medo do aluno de participar e opinar nos encontros, induzir os membros da equipe à uma constante e saudável troca de informações, bem como à uma escuta em relação aos demais integrantes da equipe, no sentido de incorporar os comentários e sugestões pertinentes que surgem nas reuniões. De fato, "não há saber mais ou saber menos, mas saberes diferentes" (FREIRE, 1987, p. 68).

Além disso, a cada novo projeto, somos obrigados a adquirir uma substancial bagagem de conhecimentos específicos, tamanhas as mudanças tecnológicas que ocorrem nas áreas de expressão e comunicação. Isso exige dos membros do LAE uma constante atualização, conhecimento das possibilidades criativas propiciadas pelas novas tecnologias, e uma grande dose 
de ousadia na busca por linguagens, métodos e técnicas inovadores. As possibilidades de atuar em várias funções em paralelo, de opinar em diferentes setores do projeto e de participar de reuniões abertas concorrem para que o aluno tenha uma visão global do processo. Incentivamos a discussão conceitual aliada à experimentação prática das múltiplas possibilidades proporcionadas pela tecnologia digital, no campo do Design. Os alunos egressos têm se destacado como profissionais versáteis, conscientes de seu papel social, e aptos a enfrentar um mercado de trabalho novo, bastante competitivo e em constante transformação.

Nossas pesquisas têm contribuído para o desenvolvimento da área de Mídia Digital no âmbito das Artes \& Design, e são apresentados e publicados nos principais congressos da área ${ }^{4}$ e em exposições artísticas ${ }^{5}$, em âmbito internacional. Acreditamos que o Design de Mídia Digital possa sensibilizar, engajar e transformar o cidadão, facilitando o entendimento de questões complexas, gerando conhecimento de forma accessível, inteligível, lúdica e interativa, e permitindo a conscientização do publico em relação a temas relevantes para o ser humano e o meio ambiente.

\section{Mídia digital para um mundo real}

Conexão, mobilidade e colaboração por meio de redes computacionais são elementos fundamentais para a sociedade atual. A exponencial disseminação da tecnologia computacional vem modificando a forma como pensamos, agimos e nos relacionamos. Hoje dirigimos automóveis com a ajuda de mapas interativos, que insistem em sugerir caminhos mais curtos e rápidos. Aguardamos a chegada de nossos táxis seguindo atentamente o movimento de pequenos carros desenhados, que se locomovem na tela dos dispositivos como num jogo infantil. Digitamos com a ajuda de corretores automáticos invasivos, que insistem em antecipar nossos pensamentos, sugerindo o uso de palavras que não necessariamente escolheríamos. Quando queremos conversar, gravamos monólogos e os enviamos - por telefone - aos amigos. E quando queremos saber como está o tempo, olhamos, agora, para baixo - para as telas de nossos celulares - e não mais para o céu.

De forma transparente e subliminar, a computação - nas suas mais variadas formas e linguagens - tornou-se uma camada invisível e essencial ao cotidiano social. Sistemas computacionais estão intrinsecamente integrados à estrutura contemporânea da existência humana. A despeito de todas as dificuldades trazidas pelas infindáveis mudanças de padrões, linguagens e suportes, vamos continuamente nos adaptando às inovações tecnológicas, que, cada vez mais, entrelaçam-se às nossas ações e reflexões. Sem dúvida, a tecnologia facilita a realização de tarefas e agiliza serviços e ações da vida cotidiana. Porém, muito mais que isso, tal combinação de realidades - física e virtual - amplia nossos limites e fronteiras individuais, e nossos espaços sociais. Os universos imersivos consequentes de programação computacional expandiram a

\footnotetext{
4 Tais como as conferências SIGGRAPH, ISEA, SIGRADI, MX Design, P\&D, SBDI, Developing Digital Diversity, dentre outras.

5 SIGGRAPH Art Gallery (Estados Unidos), Maison Européene de la Photographie (França), Stanley Picker Gallery at Kingston University (Inglaterra), Colville Place Gallery (Inglaterra), Sandton Convention Centre (África do Sul), Itaú Cultural (São Paulo, Brasil), Casa das Rosas (São Paulo, Brasil), Centro Cultural Candido Mendes (Rio de Janeiro, Brasil), Parque Lage (Rio de Janeiro, Brasil), dentre outras.
} 
capacidade perceptiva humana, que não reside mais apenas no sensório biológico. BERNAL (2015) ressalta que a ampliação tecnológica dos sistemas e dispositivos computacionais vem dando lugar a novas percepções sobre conceitos como matéria, relatividade do tempo e interação, e modificando profundamente a nossa cognição. De forma híbrida - com perfis reais e avatares imaginários - nos organizamos em coletivos e comunidades virtuais, nos quais compartilhamos "tudo o que nos parece exclusivo, incomum ou afetivamente relevante - isto é, tudo o que nos torna verdadeiramente indivíduos" (SPITZ, 2014, p. 27).

Um número crescente de organizações da sociedade civil vem utilizando as tecnologias digitais para desenvolver serviços que visam enfrentar os desafios sociais, dando lugar a uma ampla gama de inovações sociais digitais. Por meio de ações coletivas e participação ativa na formação de conhecimentos compartilhados, essas iniciativas se utilizam das tecnologias digitais para promover o engajamento cívico, abrem caminho para explorações no âmbito do design participativo, e permitem aos cidadãos promover a qualidade na vida de suas comunidades (PEREIRA Jr. e SPITZ, 2017). Seres humanos conectados a interfaces e redes digitais tornaramse a maior fonte de geração de dados do planeta. Por estarmos permanentemente conectados a dispositivos móveis e a redes sociais, e em razão do crescente número de sensores e sistemas de geo-posicionamento, da ampliação das redes sem fio e do aumento do uso de aplicativos, a quantidade de dados e informações capturadas por estes dispositivos se multiplica extraordinariamente. Somos, agora, um importante recurso para a detecção, coleta, recuperação e compartilhamento de todos os tipos de informação, com ou sem nossa intervenção, consentimento ou consciência (SPITZ et al, 2018). Esses novos paradigmas vêm operando radicais mudanças no campo do Design, que deixa de privilegiar as variáveis técnico-operacionais da escala industrial para focalizar mais diretamente as experiências, ideias e conhecimentos individuais dos usuários, e seu compartilhamento através de coletivos e comunidades virtuais. THACKARA (2008) sugere que designers devam evoluir da condição de autores individuais de objetos - ou construções - para a condição de agentes capacitadores de mudanças que envolvam grandes grupos de pessoas, incentivando o envolvimento dos cidadãos com questões pertinentes aos seus contextos.

Há uma transformação fundamental em curso. Profissionais de Design - figuras essenciais de intermediação entre o ser humano, sua cultura e sua tecnologia - devem visar a utilização das possibilidades propiciadas pelo desenvolvimento tecnológico de forma consciente, responsável e eficiente. O Design de Mídia Digital pode facilitar o entendimento de questões complexas, gerando conhecimento de forma lúdica e interativa, e permitindo a conscientização do publico em relação a temas relevantes para o ser humano e o meio ambiente.

\section{Considerações finais: o que um designer estará projetando em 2065?}

Em média, um aluno se gradua em torno de seus 25 anos de idade, e atua como profissional até completar 70 anos. Quais dos conteúdos ensinados hoje permanecerão sendo úteis, relevantes, ou mesmo essenciais à prática de um designer, durante todo o seu longo período de atuação profissional? E, especialmente, no caso do Design de Mídia Digital - área em que práticas e teorias se modificam de modo muito veloz - o que deve nortear as escolhas de um educador sobre os conteúdos a serem ensinados em suas aulas? 
Tenho me feito esse questionamento desde que iniciei minha prática educacional, e esse foi também o tema de meu Doutorado. Durante minha pesquisa, perguntei a 40 educadores de Computação Gráfica: “o que vai estar fazendo um designer no século 21?" - século esse que se iniciaria dez anos depois (as entrevistas foram realizadas de 1990 a 1991) - para saber que fatores norteavam as escolhas dos conteúdos ensinados, e verificar se o educador também se questionava sobre o que seria útil, válido e relevante para a vida profissional de seus alunos. Como resposta, ouvi de praticamente todos os entrevistados que "não se pode prever o futuro", e reclamações sobre a dificuldade que sentiam para se manter tecnologicamente atualizados. Apenas alguns poucos mencionaram a importância de se preparar o espírito dos alunos para lidar com a imprevisibilidade do futuro, e outros poucos discorreram sobre a importância de se desenvolver uma atitude curiosa em relação ao potencial do Design, em contextos futuros (SPITZ, 1993).

Quase 30 anos decorridos desde então, vemos que o cenário atual não é muito diferente. Educadores de Design encontram dificuldade para se manter atualizados em relação aos novos recursos tecnológicos que surgem incessantemente, e nem sempre estão atentos aos novos conceitos e valores trazidos por essas inovações. O rápido desenvolvimento tecnológico alavancado pela indústria dificilmente consegue ser acompanhado pela academia. Como resultado, há pouco espaço de discussão, no ambiente acadêmico de Design, sobre o espectro futuro da profissão, sobre as profundas modificações que estão ocorrendo na forma como o designer pensa e atua, e, em especial, sobre os novos conteúdos e paradigmas que devem nortear a formação de um designer que atuará profissionalmente num imprevisível cenário futuro.

Em paralelo, os alunos de Design de Mídia Digital tampouco vislumbram o infinito potencial da área em que irão atuar durante sua carreira profissional. A cada semestre, na primeira aula da disciplina que leciono há mais de 10 anos para a turma de calouros de Mídia Digital, pergunto aos alunos em que nicho da área de Design pretendem atuar. A reação dos alunos é quase instantânea: "animação" e "design de jogos" são as respostas mais frequentes. É como se todos já soubessem exatamente o que estarão fazendo em sua vida profissional - e, ainda pior - como se sua vida profissional se restringisse a um período de alguns poucos anos apenas, após a sua formatura. Então, na tentativa de estimulá-los a pensar em outras alternativas, pergunto à turma: “E o que um designer vai estar projetando em 2065?". Com espanto e surpresa, os alunos se entreolham, alguns até arriscam um palpite, mas a grande maioria apenas cita exemplos de tecnologias que já estão em uso, ou menciona cenas conhecidas de filmes de ficção cientifica. Ninguém parece se interessar pelo que ainda não viu ou não conhece. Essa falta de interesse pelo novo faz com que, ao longo do curso, os alunos acabem por repetir velhas fórmulas, baseadas no que já existe, desperdiçando as inúmeras oportunidades existentes que poderiam levá-los a desenvolver experiências inovadoras, projetos ousados e descobertas originais.

Para ilustrar as mudanças ocorridas no campo do Design, cito então minha própria e inusitada trajetória. A data de 2065 é intencional, pois, tendo ingressado na graduação de Design em 1975, encontrava-me, há exatos 45 anos, na mesma situação de meus alunos calouros deste ano (que estão a exatos 45 anos de distancia em relação ao ano de 2065). Sem dúvida, em 1975 o ensino de Design era bastante diferente do atual: o computador pessoal ainda não existia, tampouco a Internet, as câmeras digitais, celulares, redes sociais, sensores e equipamentos para imersão virtual. Como poderia esperar então que, depois de formada, estaria desenvolvendo projetos em 
Computação Gráfica, multimídia e sites para a Web, instalações interativas, interfaces gráficas e aplicativos para celulares, pesquisas em Realidade Virtual, dentre outras coisas? Ao final da palestra, os alunos finalmente entendem a razão da pergunta inicial - como poderia eu, em 1975, já saber o que estaria projetando 45 anos depois, em 2020? A mensagem, portanto, é a de que alunos de Mídia Digital não deveriam definir sua opção profissional de forma tão categórica, logo ao início de sua graduação, mas, sim, permanecer flexíveis e abertos às novidades que surgirão no decorrer do percurso.

Não sabemos, de fato, o que acontecerá dentro de 45 anos. Em virtude das mudanças tecnológicas, que afetam diretamente nossas relações humanas e práticas profissionais, prever a esfera de atuação de um designer em 2065 - ou mesmo num futuro bem mais próximo - torna-se quase impossível. Mas são exatamente essas incertezas, dúvidas e questionamentos que fazem com que o Design se reconstrua e se renove constantemente, buscando estar em compasso com as modificações de nossa sociedade e, em alguns casos, à frente delas, abrindo caminhos ainda inexplorados. Indagações como essas devem guiar nosso espírito de curiosidade, manter viva nossa inquietação artística e científica, e nortear nossa atividade educacional. E é exatamente isso o que valorizamos no âmbito educacional do Design de Mídia Digital, e, em especial, no Laboratório de Arte Eletrônica da PUC-Rio.

Embora não se saiba o que um designer vai estar projetando em 2065, pode-se prospectar com base nas pesquisas cientificas e desenvolvimento de projetos em curso - algumas das modificações que impactarão a sociedade durante este século: uso de carros autônomos e inteligentes, realidades construídas artificialmente, projetos para a preservação do planeta contra o aquecimento global, avanços no campo da medicina virtual, sistemas inteligentes de prevenção de acidentes, robôs humanizados, plataformas com interfaces naturais para expressão e comunicação de ideias, sistemas de impressão de elementos complexos (tais como alimentos e órgãos vitais), dentre muitas outras inovações que ainda irão surgir.

Há que se formar profissionais de Design com um conjunto diverso de interesses e de saberes, que conheçam e questionem os fundamentos e as consequências do desenvolvimento e uso ininterrupto das tecnologias digitais. Justamente por ser nosso futuro tão absolutamente imprevisível, cabe ao designer um papel fundamental na construção dessa passagem. É preciso cuidar para que a tecnologia esteja sempre - e de fato - a serviço da melhoria da qualidade de vida no planeta.

Na verdade, não importa saber o que estaremos projetando em 2065.

O que realmente importa - durante essa longa jornada - é termos a certeza de que estamos indo pelo caminho certo.

\section{Agradecimentos}

Nossos agradecimentos a todos os professores, alunos e colaboradores que fizeram parte das diversas equipes do Laboratório de Arte Eletrônica da PUC-Rio, ao Departamento de Artes \& Design da PUC-Rio, e a todas as demais instituições parceiras do LAE, por seu apoio, incentivo e confiança. 


\section{Referências}

BERNAL, R. Imersão evolutiva, arte digital, ciência e tecnologia. ARJ - Art Research Journal, v.2, n. 2, p. 11-122, 25 set. 2015.

BERNARDINO, P. Arte e tecnologia: intersecções. ARS São Paulo, v.8, n. 16, p. 3963, 2010. Disponível em: https://doi.org/10.1590/S1678-53202010000200004. Acesso em: 28 agosto 2019.

COX, D. Computer Art/Design Curricula in Universities: Beyond the Traditional Approach. In: ACM SIGGRAPH 1987, Teaching Computer Graphics: An Interdisciplinary Approach, SIGGRAPH 87 Educator's Workshop Proceedings. New York: ACM SIGGRAPH, 1987, p. 207-233.

FLORINDO, N. D.; SILVA, T. A. da; CARVALHO, J. M. C. de. Arte Digital, Arte Eletrônica e Arte Midiática: uma proposta taxonômica. In: ROCHA, C. (Org). Anais do V Simpósio Internacional de Inovação em Mídias Interativas Goiânia: Media Lab / UFG, 2018. p. 102112.

FREIRE, P. Pedagogia do oprimido. $17^{\text {a }}$ ed. Rio de Janeiro: Paz e Terra, 1987.

HOLANDA, G.; SPITZ, R. O invisível tornado visível. In AMARAL, L.; GEIGER, A. (orgs.). IN VITRO, IN VIVO, IN SILICIO: ensaios sobre arte, ciência, tecnologia e espiritualidade, 2008.

NASCIMENTO, B.E.M.; GAMBA Jr., N.; OLIVEIRA, L.; PEREIRA, M. G.; SPITZ, R.; GLEISER, S.; Perez, C.; VIANNA, C.; CAVALCANTE, T.; VOLCHAN, E. Neurociências, artes gráficas e saúde pública: as novas advertências sanitárias para maços de cigarros. Hist. cienc. Saúde - Manguinhos [online]. 2010, vol.17, suppl.1 p. 243-252. Disponível em: http://dx.doi.org/10.1590/S0104-59702010000500014. Acesso em: 10 maio 2019.

PEREIRA Jr., C.; SPITZ, R. Enabling platforms for citizen participation: opening design to digital social innovation. DIS Revista Semestral del Departamento de Diseño, n. 1, p. 4048, Julio-Deciembre 2017. Disponível em:

https://ibero.mx/sites/all/themes/ibero/descargables/publicaciones/01_Inclusion_y_Sociedad. pdf. Acesso em: 15 abril 2019.

SPITZ, R. (ed.) Desorientação e colaboração no cotidiano digital. Rio de Janeiro: Rio Books, 2014, 284p.

. Intimate Science for the Naked Eye. In: DOMSCHKE, G., FERRAN, B., MAHFUZ, R.; WOLFSBERGER, A. (eds). Paralelo - Unfolding Narratives: in Art, Technology \& Environment / Paralelo - Narrativas em Percurso: sobre Arte, Tecnologia e MeioAmbiente. British Council, AHRC (Arts \& Humanities Research Council) \& Mondriaan Foundation, Virtueel Platform, 2010. p. $216-225$

De quoi avez-vous faim? (Você tem fome de que?). In: Anomalie digital_arts \#5. (Org.). ://brasil - Festival Art Outsiders 2005. 01 ed. Orleans: Editions HYX, 2005. v. 01, p. 236-249.

Você Tem Fome de Que? In: CONGRESSO DA SOCIEDADE IBEROAMERICANA DE GRÁFICA DIGITAL, 8, SIGRADI 2004, Porto Alegre. Anais do VIII Congresso da Sociedade Iberoamericana de Gráfica Digital, Porto Alegre, Brasil: UNISINOS, 2004, p. 424-427.

Netizens, Net-fringers and Outsiders. In: ACM SIGGRAPH 2001. Electronic Art and Animation Catalog - Computer Graphics Annual Conference Series, ACM SIGGRAPH, 2001. New York: ACM SIGGRAPH, 2001. p.133.

Teaching Computer Graphics in Brazil: Social Commitment, Creativity and Passion - Against All Odds! In: ACM SIGGRAPH, 2000, SIGGRAPH'2000 Conference Abstracts 
and Applications, Computer Graphics Annual Conference Series. New York: ACM SIGGRAPH, 2000. v.1, p.63-65

Dirty Hands on the Keyboard: In Search of Less Aseptic Computer Graphics Teaching for Art \& Design. In: CONGRESO IBEROAMERICANO DE GRAFICA DIGITAL, 3., SIGRADI Conference Proceedings 1999, Montevideo (Uruguay): SIGRADI 1999, September 29th - October 1st 1999, pp. 13-18

O papel da Computação Gráfica no ensino de Artes \& Desenho Industrial: a percepção de dirigentes, docentes e alunos. Tese de Doutorado. Rio de Janeiro: Departamento de Educação, PUC-Rio, 1993.

Cultural differences \& visual acuity testing. Information Design Journal, Vol. 5:3 (1989), pp. 209-233.

Guide-lines for the design, production and application of eye-testing materials for pre-literate children from different cultural groups, Dissertação de Mestrado, Londres: Central School of Art \& Design, 1983.

SPITZ, R.; GAMBA Jr., N. Design \& campanhas anti-tabagismo: as novas imagens e advertências a serem impressas nos maços de cigarro no Brasil. In: CONGRESSO INTERNACIONAL DE DESIGN DA INFORMAÇÃO, 3. Anais do $\mathbf{3}^{\circ}$ Congresso Internacional de Design da Informação. Curitiba: 2007. s/n.

SPITZ, R.; GAMBA Jr., N.; OLIVEIRA, B. J. de; LANSKY, S. Sentidos do Nascer: efeitos de uma exposição interativa na transformação da percepção sobre o parto e nascimento. DIS Revista Semestral del Departamento de Diseño, n. 1, p. 125 - 134, Julio-Dec.2017. Disponível em: https:/ibero.mx/sites/all/themes/ibero/descargables/publicaciones/ 01_Inclusion_y_Sociedad.pdf. Acesso em: 15 abril 2019.

SPITZ, R.; PEREIRA Jr., C.; QUEIROZ, F.; LEITE, L. C.; DAM, P.; REZENDE, A. C. Gamification, citizen science and civic technologies: in search of the common good. Strategic Design Research Journal, 11(3): 263-273, September-December 2018, Unisinos. Disponível em: http://revistas.unisinos.br/index.php/sdrj/article/view/sdrj.2018.113.11. Acesso em: 19 abril 2019.

SZKLO, A. S.; COUTINHO, E. S. F.; GAMBA Jr., N.; SPITZ, R. Gains of stopping smoking: portraits of the dialogue between public health promotion, art and design. International Journal of Epidemiology, 2009, v. 38, p. 1459-1463.

THACKARA, J. Plano B: o design e as alternativas viáveis em um mundo complexo. São Paulo: Saraiva, 2008.

\section{Sobre o autor}

Professora Associada e Coordenadora do Laboratório de Arte Eletrônica do Departamento de Artes e Design da PUC-Rio. Graduada em Desenho Industrial e em Comunicação Visual pela PUC-Rio (1979), pós-graduada em Advanced Typographic Design pela London College of Printing (Inglaterra, 1982), Mestre em Graphic Design pela Central School of Art \& Design (Inglaterra, 1983), Doutora em Educação pela PUC-Rio (1993), com pós-doutorado em Arte Eletrônica pela University of California - Berkeley (EUA, 2002) e pelo CADRE Laboratory for New Media/ San Jose State University, California (EUA, 2003).

rejane@puc-rio.br 